\title{
Nurses' practice in preventing postoperative wound infections: an observational study
}

Objective: Surgical site infections (SSIs) are serious postoperative complications that may lead to undesired patient outcomes. Previous research has used survey and chart audit methods to describe wound care practices. However, little research has been published using contemporaneous observations to describe the surgical wound management practices of nurses. The aim of this study was to prospectively describe surgical nurses' postoperative wound care practices and the extent to which observed surgical wound practices aligned with evidence-based guideline recommendations.

Method: In this cross-sectional prospective study, we observed a convenience sample of 60 nurses from four surgical units using a specifically developed observational audit tool. Inter-rater reliability for this tool was assessed during the observation period.

Results: Of 60 observed episodes of wound care, post-procedure hand hygiene ( $n=49,81.7 \%)$ was less evident compared with preprocedure hand hygiene practice $(n=57,95 \%)$. Over one-third of nurses observed did not correctly use clean gloves $(n=16,38.1 \%)$ and one in five did not properly use sterile gloves ( $n=4,22 \%)$. More than half of surgical nurses $(n=37,61.7 \%)$ did not educate patients on postdischarge wound management. Fewer than a quarter $(n=14,23.3 \%)$ of wound care events were recorded on both wound assessment charts and patients' progress notes. Inter-rater reliability testing indicated good agreement (intra-class correlation coefficient $0.859 ; 95 \% \mathrm{Cl}$ : 0.771-0.923; $p<0.0005)$.

Conclusion: Despite surgical wound care guideline recommendations on aseptic technique compliance, patient education, wound assessment and documentation practices, there is a clear gap between recommended and observed wound care practice. This study highlights an area where clinical practice is not reflective of evidencebased recommendations, suggesting that to minimise SSI as an adverse event, practice should be evaluated and strategies incorporating evidence into practice are explored.

Declaration of interest: No conflict of interest has been declared by the authors.

surgical wounds $\bullet$ observations $\bullet$ clinical practice guidelines $\bullet$ aseptic technique $\bullet$ chart audit $\bullet$ education

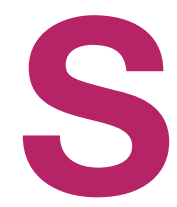

urgical procedures have been performed for decades to treat a diverse range of conditions and the number performed is expected to rise. ${ }^{1}$ In the US, about 16 million surgeries were performed in acute care hospitals in $2010 .^{2}$ In France, it is estimated that about seven million surgical procedures are performed annually. ${ }^{3}$ The majority of these procedures result in wounds that heal by primary intention, that is, where the wound is sutured, glued or stapled so that the edges are closed directly, leaving a minimal, cosmetically acceptable line. ${ }^{4}$ There are a number of risks associated with surgical procedures, including surgical site infections (SSIs). ${ }^{1}$ It is estimated that $2-5 \%$ of inpatient surgical procedures will experience an SSI, ${ }^{5}$ defined as any infection taking place within 30 days after a

S. Ding, ${ }^{1,2}$ RN, MN, Clinical Nurse; F. Lin, ${ }^{1,2,3}$ RN, PhD, Senior Lecturer; A.P. Marshall, , $1,2,3,4$ RN, PhD, Professor of Acute and Complex Care Nursing; B.M. Gillespie, ${ }^{1,2,3,4} \mathrm{PhD}, \mathrm{RN}, \mathrm{RN}$, $\mathrm{PhD}$, Professor of Patient Safety

E-mail: f.lin@griffith.edu.au

1 School of Nursing and Midwifery, Griffith University, Australia 2 Gold Coast Hospital and Health Service 3 Menzies Health Institute Queensland, Griffith University, Australia 4 National Centre for Research Excellence in Nursing, Griffith University, Australia surgical operation or within one year of surgical implantation of prosthesis or foreign body. ${ }^{6}$

SSIs are a major contributor to overall health-care associated infections (HAIs) worldwide. In the US, the Centers for Disease Control and Prevention (CDC) prevalence survey claimed that around 157,500 SSIs were associated with inpatient surgeries in $2011 .{ }^{7}$ This was the most common HAI, responsible for $31 \%$ of all HAIs among hospital admissions in the US. ${ }^{7}$ In France, it has been estimated that the incidence rate of SSI is around 140,000 to 200,000 every year. ${ }^{3}$ Furthermore, the incidence of SSIs in developing countries is significantly higher than proportions documented in developed countries. ${ }^{8}$ While urinary tract infection is the most common HAI in developed countries, SSI is the most common infection-affecting up to one-third of surgical patients-in developing countries when resources are limited, and it has an incidence rate nine times higher than that of developed countries. ${ }^{9}$ According to a systematic review and meta-analysis of articles published from 1995 to 2008 in developing countries, such as Africa, the Eastern Mediterranean and South East Asia, SSI occurs in 5.6 per 100 surgical procedures and for two decades has been the most 
common infection in hospitals in comparison with ventilator-associated pneumonia, bloodstream infection and urinary tract infection. ${ }^{8}$ In China, according to three point-prevalence surveys from 2012 to 2014, SSI was the second most common HAI, followed by pneumonia. ${ }^{10}$

SSIs have a substantial impact on the global healthcare system and have been associated with increased hospital stay and extra health-care costs. ${ }^{11}$ In the US, the length of hospital stay can double for patients with a SSI and result in higher health-care costs. ${ }^{12}$ In a US study comprising 67 (53\%) hospitals in North Carolina, SSI was responsible for $87-91 \%$ of overall HAI-related costs. ${ }^{13}$ Zimlichman et al. claimed that SSI incurred a cost of more than US\$20,000 per admission from 1986 to $2013 .{ }^{14}$ According to a study conducted in the UK in 2013, the average extra length of stay due to SSI was 10 days and the average additional cost per patient was £5239. ${ }^{15}$ In France, post-surgery infections resulted in an annual cost of 57,892,715 EU in 2010. ${ }^{16}$

In UK, patients' experiences of SSI were studied, and results suggested that SSI impacts patient outcomes by causing distress, discomfort, or even death. ${ }^{17}$ In France, patients experiencing a postoperative infection had a 4-15 times higher mortality risk in 2009. ${ }^{16}$ Despite recent advances in medicine and medical care delivery, SSI continues to be a major cause of morbidity and mortality worldwide. $1,3,8,13$

\section{Literature review}

According to a recent systematic review in the US hospitals, up to $55 \%$ of SSIs may be preventable with current evidence-based guidelines. ${ }^{18}$ Wound care practice focuses on the importance of SSI surveillance, reducing the risk of SSIs and promoting prevention of SSIs. ${ }^{4}$ 19, 20 The development of clinical practice guidelines has provided updated surgical wound care standards and position statements relating to SSI prevention. ${ }^{4}, 19,20$ These wound care guidelines, published in different international contexts, include those from the Healthcare Infection Control Practices Advisory Committee (HICPAC), adopted by the CDC, ${ }^{20}$ from the Australian Wound Management Association (AWMA) ${ }^{19}$ and those produced for the National Institute for Health and Care Excellence (NICE) ${ }^{4}$. They focus on the importance of strategies that are attributed to reducing the potential for SSI (Table 1).

According to Rowley et al, $^{21}$ aseptic technique has been developed to standardise clinical practice to ensure asepsis is achieved through hand hygiene, nontouch technique and using new sterilised equipment. Aseptic principles should be used during any invasive procedures that could potentially breach the body's defence mechanisms. ${ }^{22}$ In 2010, the Australian National Health and Medical Research Council published a guideline for the prevention and control of infection in health care, ${ }^{23}$ which highlighted that surgical aseptic technique should include ensuring a strict aseptic field when dealing with surgical, complex or large wounds.
Observance of asepsis and/or wound field technique is important to recognise early signs of wound infection and to minimise the risk of wound contamination. ${ }^{22}$

The NICE guideline includes consideration of patient education, ${ }^{4}$ which states that nurses should give information and advice to patients and carers throughout all stages of their care. Information should include the risks of developing SSIs, how to reduce them and how SSIs are managed. ${ }^{4}$ The guidelines recommend that clinicians provide the patient and/or their carers with assessment outcomes and education that is appropriate to their age and cognitive status. Clinical decision-making depends on comprehensive individual assessment, clinical signs and symptoms of wound or systemic infection, risk factors and wound healing environment. ${ }^{19}$ According to AWMA, ${ }^{19}$ conducting a comprehensive wound assessment is the best way to determine the status of the wound to ascertain whether the wound is progressing and achieving the desired healing goal. Documentation of wound assessment facilitates evaluation of wound healing over a period of time, and thus is essential to promote early recognition and treatment for SSIs. ${ }^{19}$

Clearly, there is an expectation that wound care practice is underpinned by research, however, evidence suggests that clinical practice guidelines are often not used by clinicians. ${ }^{24} \mathrm{~A}$ recent survey in the US found that compliance with SSI prevention guidelines was poor at two county hospitals 25 and clinicians' adherence to surgical care bundle tactics such as the 'Surgical Care Improvement Project' to prevent SSIs was disappointing. ${ }^{26}$ The extent to which existing clinical practice is in line with recommendations contained within these evidence-based clinical practice guidelines is unknown, highlighting an opportunity to evaluate surgical wound care practices and identify interventions that might be required to implement and/or sustain recommendations on the prevention of SSI in clinical practice. To our knowledge, no audit tool is available and no cross-sectional observational study has been conducted on nurses' management of surgical wounds healing by primary intention. ${ }^{27}$

\section{Aims and objectives}

The overall aim of this research was to describe surgical nurses' practice in relation to adherence to HIPAC, ${ }^{20}$ $\mathrm{NICE}^{4}$ and $\mathrm{AWMA}^{19}$ guidelines. We did not intend to test a hypothesis about group differences, rather to describe practice, and observe the extent to which the clinical practice regarding surgical wound management reflected evidence-based recommendations in an acute care tertiary hospital in Australia. Thus, the results of this study will provide pilot information that will be used to inform future quality improvement studies in wound care management.

\section{Methods}

Design, setting and sample

This was a cross-sectional, prospective observational 


\section{practice}

\section{Table 1. Guidelines/standards on surgical wound care}

\begin{tabular}{|c|c|c|}
\hline Criterion number & Guideline recommendations & References \\
\hline $\begin{array}{l}\text { 1. Dressing management: use an aseptic } \\
\text { non-touch technique for change or remove } \\
\text { dressings }\end{array}$ & $\begin{array}{l}\text { - } \text { Leave dressing intact for at least } 48 \text { hours post procedure } \\
\text { - } \text { Hemond hygiene before dressing change, using soap and water or alcohol gel } \\
\text { - Wash hands after removing old dressing } \\
\text { - Change gloves after removing old dressing } \\
\text { - Use clean gloves in non-touch technique (gloved hand does not touch wound, and/ } \\
\text { - } \text { - Use dressing) } \\
\text { - Aseptic fields } \\
\text { - Environmental control: no other avoidable infection risk factors (such as bed making, } \\
\text { - Watients using commodes, or urinal bottles with urine in them) } \\
\text { - } \text { eye protection }\end{array}$ & $\begin{array}{l}\text { NICE } 2008 \\
\text { CDC } 1999 \\
\text { AWMA } 2010\end{array}$ \\
\hline 2. Cleansing solution & $\begin{array}{l}\text { - Use sterile saline for wound cleansing from post-op to } 48 \text { hours after surgery if } \\
\text { dressing needs to be changed } \\
\text { - Use tap water for wound cleansing after } 48 \text { hours if dressing needs to be changed, } \\
\text { and if the wound has separated or has been surgically opened to drain pus }\end{array}$ & NICE 2008 \\
\hline 3. Patient education & $\begin{array}{l}\text { - Advise patients that they may shower safely } 48 \text { hours after surgery } \\
\text { - Educate patient on how to care for wound after discharge and follow up wound care }\end{array}$ & $\begin{array}{l}\text { NICE } 2008 \\
\text { CDC } 1999 \\
\text { AWMA } 2010\end{array}$ \\
\hline 4. Topical antimicrobial agents & $\begin{array}{l}\text { - Topical antimicrobial agents are not recommended on surgery wounds healing } \\
\text { by primary intension }\end{array}$ & NICE 2008 \\
\hline $\begin{array}{l}\text { 5. Wound assessment method: the nurse } \\
\text { checks the wound and looks for signs of SSI } \\
\text { (heat, redness, pain and swelling, and fever) }\end{array}$ & $\begin{array}{l}\text { - Direct observation } \\
\text { - Assessment tools used }\end{array}$ & $\begin{array}{l}\text { CDC } 1999 \\
\text { AWMA } 2010\end{array}$ \\
\hline 6. Documentation contents & $\begin{array}{l}\text { - Type of wound } \\
\text { - } \text { Duration of wound } \\
\text { - } \text { Location of wound } \\
\text { - Clinical characteristics of wound bed (red, pink, yellow, black, undermined) } \\
\text { - Wound edge appearance (callus and scale, maceration, erythema, oedema) } \\
\text { - Periwound appearance } \\
\text { - } \text { - Infection: signs and symptoms of infection documented. } \\
\text { - Wound pain } \\
\text { - Presence of foreign bodies } \\
\text { - Prior wound treatments and their therapeutic outcome }\end{array}$ & AWMA 2010 \\
\hline $\begin{array}{l}\text { 7. Management of abnormal wound } \\
\text { assessment results }\end{array}$ & $\begin{array}{l}\text { - Reporting of abnormal findings according to hospital protocol } \\
\text { - Dressing choice appropriate for wound condition } \\
\text { - Referral to wound care specialist } \\
\text { - Consult another more experienced staff member } \\
\text { - Notify surgeon or medical officer } \\
\text { - Antibiotics use }\end{array}$ & $\begin{array}{l}\text { NICE } 2008 \\
\text { CDC } 1999 \\
\text { AWMA } 2010\end{array}$ \\
\hline 8. Documentation of abnormal wounds & - Explicitly document if the wound is abnormal & AWMA 2010 \\
\hline
\end{tabular}

study. As this study aimed to describe contemporaneous wound care practice before a larger scale implementation programme, we conducted a pilot study. A pilot study is considered appropriate to assess the feasibility of implementation of a novel intervention, recruitment, assessment procedures, new methods and randomisation. ${ }^{28,29}$ As this was a pilot study, the target sample size was set at 60-100 participants, which is considered appropriate. ${ }^{30}$ This study was undertaken in a 750-bed Australian university hospital from February to April 2014. The hospital provides acute care services including intensive care, general surgery, and general medicine. In a convenience sample of 60 surgical nurses, we observed 60 wound care episodes of surgical wound management (dressing changes) across neurovascular, general surgery, and orthopaedic wards as well as in the intensive care unit (ICU) in an acute tertiary hospital in Australia. Each surgical nurse was observed only once during this study.

We observed the practices of nurses managing 'clean' surgical wounds healing by primary intention. A 'clean' wound is defined as a surgical incision in which no 
inflammation was encountered during surgery, where there was no breach of aseptic technique, and which did not involve the respiratory, alimentary or genitourinary tracts. ${ }^{20}$ This study was approved by Human Research Ethics Committee (HREC) from the Gold Coast University Hospital (HREC/13/QGC/84) and Griffith University (NRS/44/13/HREC).

\section{Data collection}

We developed a data collection tool to allow us to describe contemporaneous surgical wound management practices used to minimise the risk of SSIs. The observational tool, developed specifically for this study, was based on several clinical practice guidelines and standards relating to SSI prevention that included hand hygiene, wound cleansing and general asepsis-namely, those from the AWMA, ${ }^{19}$ HICPAC, ${ }^{20}$ and NICE. ${ }^{4}$ Prior to the use of this tool, it was rigorously tested in the clinical setting by two trained observers relating to item clarity, and its overall flow and format. Items within the audit tool included postoperative surgical wound management practice behaviours to determine the extent to which evidence-based recommendations were followed to prevent SSI in the clinical environment. Inter-rater reliability was assessed using the intra-class correlation coefficient (ICC). The ICC score was calculated to define consistency among two raters. The ICC value was 0.859 (95\% CI: 0.771-0.923, p<0.0005) and was considered adequate for internal consistency. ${ }^{31}$ One of the two raters conducted all observations for the project.

Participant demographic data including age, gender, employment classification, highest qualification, years worked in the participating hospital, years of nursing experience and employment status were collected before observations. In accordance with the World Health Organization (WHO) guidelines on hand hygiene in health care, ${ }^{32}$ the observation period in this study commenced when the nurses introduced themselves and asked patients' permission to perform dressing changes and concluded when the dressing was finished and hand hygiene performed. Clinical documentation of the episode of wound care was prospectively reviewed. Additional data related to wound care practices of nurses were sourced from the patient's medical record where required.

\section{Data analysis}

An audit was conducted by two trained data collectors to verify data validity. Two research assistants who were trained in data analysis checked data. The data were cleaned and transcribed from the data collection sheets. Data entered into the Social Sciences Statistics Program (SPSS) (version 21.0, IBM, IL) were checked for correctness (i.e. coding) and completeness (i.e. missing values). Descriptive statistics were used to describe sample characteristics using absolute (n) and relative frequencies (\%) for each of the items on the observational tool. These items included clinical area, employment classification, professional qualification, employment status, and clinical characteristics of patients and their wounds (e.g., duration of wound, location of wound, wound dimension, surgical specialty and wound location).

\section{Results}

In this study, 60 episodes of wound care were observed. About three-quarters $(n=39,65 \%)$ of the observations were completed in neurosurgical and general surgical units (Table 2). Table 3 shows the demographic and clinical characteristics of surgical nurses. Nurses' ages ranged from 20 to 62 years with a mean age of 33.8 years ( $\mathrm{SD}=11.46$ years). Table 4 shows the clinical characteristics of observed wounds, about threequarters $(n=43,71.7 \%)$ of the wounds were the result of orthopedic or plastic surgery, with most wounds located on the knees, legs and toes $(n=26,43.3 \%)$.

\section{Observed wound management practices}

The estimated time spent on simple surgical wound dressings was 10-15 minutes. A total of 57 nurses (95\%) were observed to decontaminate their hands before dressing changes using soap and water or alcohol gel (Table 5). Post-procedure hand hygiene was performed less frequently and observed for 49 participants $(81.7 \%)$. In $85 \%$ of wound dressing episodes $(n=51)$, nurses were observed to set up aseptic fields and sterile wound dressing kits were used. Clean gloves using a non-touch technique were indicated in 42 observation episodes (70\%) (Table 6), however, only $26 / 42$ nurses (61.9\%) used clean gloves accurately without touching the wounds. A moderate proportion of nurses observed $(n=16,38.1 \%)$ either did not use any gloves when clean gloves were indicated $(n=2,4.8 \%)$, or used sterile gloves instead of clean gloves $(n=8,19 \%)$, or clean gloves contaminated wounds/dressings, breaching aseptic, non-touch technique $(n=6,14.3 \%)$. Sterile gloves were required in 18 occasions (77.8\%), yet $22.2 \%$ of nurses $(n=4)$ were observed to have used sterile gloves incorrectly. Three nurses (16.7\%) used clean gloves when sterile gloves were necessary, and one nurse $(5.5 \%)$ used sterile gloves but had touched areas outside of the aseptic fields.

Wound care education, including how to manage wound after discharge and follow-up wound care, was observed in about $30 \%$ of the time $(n=18)$. Most patients $(n=47,78.3 \%)$ were not given information on being able to shower safely 48 hours after surgery. Environmental hygiene measures such as having a clutter-free bedside, with the absence of urinals, and other objects that act as potential sources of contamination, were observed during all episodes of wound care.

\section{Observed wound assessment and documentation}

All of the nurses observed $(n=60)$ used direct visual observation to check the wounds and looked for signs of infection, such as redness, pain, heat, swelling and 
Table 2. Clinical area

\begin{tabular}{|c|c|c|}
\hline Clinical area & $\begin{array}{l}\text { Nurses } \\
\text { observed }\end{array}$ & Percentage \\
\hline Intensive care unit & 10 & 16.7 \\
\hline Neurovascular & 20 & 33.3 \\
\hline Orthopedic ward & 11 & 18.3 \\
\hline General surgery & 19 & 31.7 \\
\hline Total & 60 & $100 \%$ \\
\hline
\end{tabular}

Table 3. Nurses' demographic characteristics

\begin{tabular}{|c|c|c|}
\hline $\begin{array}{l}\text { Demographic } \\
\text { characteristic }\end{array}$ & Number & Percentage \\
\hline \multicolumn{3}{|l|}{ Employment classification } \\
\hline Enrolled nurses & 7 & 11.7 \\
\hline Bedside registered nurse & 46 & 76.6 \\
\hline Senior registered nurse & 7 & 11.7 \\
\hline Total & 60 & $100 \%$ \\
\hline \multicolumn{3}{|l|}{ Professional qualification } \\
\hline Diploma & 7 & 11.7 \\
\hline Bachelor & 47 & 78.3 \\
\hline Graduate certificate & 3 & 5.0 \\
\hline Master & 3 & 5.0 \\
\hline Total & 60 & $100 \%$ \\
\hline \multicolumn{3}{|l|}{ Employment status } \\
\hline Full-time & 14 & 23.3 \\
\hline Part-time & 45 & 75.0 \\
\hline Casual & 1 & 1.7 \\
\hline Total & 60 & $100 \%$ \\
\hline
\end{tabular}

fever (Table 5). Fourteen wound assessment findings $(23.3 \%)$ were recorded on both progress notes and wound charts; wound location was the most frequently documented characteristic $(n=27,45 \%)$ on these two documents. One-quarter of wound care episodes $(n=15)$ were not documented anywhere in the patient medical record.

The majority ( $n=44,73.3 \%$ ) of wound assessments were documented in the patients' progress notes (Table 5). The most documented wound characteristic in progress notes was wound location $(n=21,35 \%)$. Wound edge appearance was only documented once $(1.7 \%)$ in a patient's medical record. Hospital-based specific wound assessment documentation charts were only used to document $25 \%(n=15)$ episodes of wound care. From field notes, we noticed that, of the 15 occasions where wound assessment charts/tools were used, there were always one or more aspects of the tools that were not completed. On average, less than $50 \%$ of the contents on wound charts were completed after wound assessment (range 6.7-73.3\%). The type of wound exudate was the most commonly documented assessment characteristic ( $n=14,93.3 \%)$ on hospital specific wound charts. From the combined documentation in progress notes and wound assessment tools, there was limited, if any documentation with regard to wound duration, incisional pain, presence of foreign body and periwound treatment.

\section{Discussion}

The aim of this study was to describe, through observations, nurses' surgical wound practices in an acute university hospital in Australia. To the best of our knowledge, ${ }^{27}$ this study is the first to examine nurses' practices prospectively, and thus provides a baseline for further research in this area. The results of this study suggest that there are some incongruencies in the uptake of guidelines on aseptic technique in surgical wound care. We observed that hand hygiene before and after removing old dressings was carried out on most occasions; however post-procedure hand hygiene was performed suboptimally for about $20 \%$ of observations. Hand hygiene is crucial to the application of standard precautions for infection control and SSI prevention. ${ }^{20 \text {, }}$ 32 According to HIPAC and $\mathrm{WHO}^{32}$ guidelines, hand hygiene should be performed before and after contact with patients or surgical procedures to reduce SSIs. Yet, Swenne and Alexandrén, ${ }^{33}$ suggested that hand hygiene practice among clinicians is suboptimal and implementation of hand hygiene into daily routine has been difficult to achieve. Our observational results suggest that hand hygiene practices before and after direct patient contact were inconsistent and sterile gloves were not always used before handling sterile dressing equipment. before handling sterile dressing equipment. Our audit confirms these findings and suggests that nurses' hand-washing, especially postprocedure hand hygiene, is inconsistent with recommended practice and is an area warranting targeted intervention. Inconsistency in hand hygiene in our study may have been attributed to the busy nature of surgical wards, multitasking of nurses, and the protracted time spent on each wound care episode. At this stage, it is not clear to us why hand hygiene is inconsistent and why nurses perform this less frequently post procedure. Future interview data may assist to uncover this, and identification of strategies to improve clinical environments to increase hand hygiene compliance will be timely.

We also found that the correct use of clean gloves in non-touch techniques occurred in less than half of the episodes of wound care, where their use was indicated. Our field notes indicated that the majority of nurses did not use clean gloves properly because: when clean gloves were used, gloved hands still touched wounds during procedures; sterile gloves were used in some wounds where only clean technique was required; or gloves were not used at all. The national evidence-based guidelines for 
preventing healthcare-associated infections ${ }^{34}$ in the UK have recommended that gloves be donned for invasive procedures, contact with sterile sites, breached skin or mucous membranes; otherwise the risk of exposure to blood or body fluids is increased. AWMA ${ }^{19}$ standards also recommend that sterile gloves be applied for aseptic procedures involving sterile sites, such as wounds. In this study, when touching wounds or dressings was unavoidable, a small number of nurses did not use sterile gloves appropriately $(4 / 18,22.2 \%)$ and contaminated their sterile gloves during wound dressing change. During data collection we observed that some nurses failed to establish an aseptic field or use personal protective equipment when risk of contamination, such as splashing of body fluids, was high. Recommended clinical practice guideliens have emphasised that the use and selection of personal protective equipment should be based on an assessment of contamination risk from blood or body fluids and the risk of transmission of microorganisms between health-care workers and patients. ${ }^{4,34}$

According to Skoufalos et al., ${ }^{35}$ clinicians need to focus on the role of patient education to provide information and instructions before the surgical procedure, and strategies for SSI prevention and reducing SSI risk. Clinical guidelines published by bodies, such as the $\mathrm{CDC}^{20}$ and $\mathrm{AWMA},{ }^{19}$ have focused on the role of patient education on risk management to prevent SSI, improving the quality of wound care management and outcomes associated with SSI, and clinical practice guidelines recommend patient education as an SSI prevention strategy following surgery. ${ }^{19,} 20$ Our results indicated that most postsurgical patients did not receive wound care education during the observational period or after dressing changes. For example, in the 60 episodes of wound care that we observed, no patient was advised that they could have a shower 48 hours after surgery, as recommended by the NICE guidelines. ${ }^{4}$ We observed that small number of surgical patients received education on wound management, a strategy recommended by the AWMA. ${ }^{19}$ However, nurses may have provided education during other occasions that we have not observed. To the best of our knowledge, no published studies have been conducted that have described nurses' practice around giving wound care education to patients following surgery. We found only one study that retrospectively reviewed postoperative surgical patients' wound care notes and revealed that wound care patient education was inconsistent. ${ }^{36}$

We also identified a significant shortfall in wound care documentation in progress notes. Although less than three-quarters of wound assessment results were documented in the patients' progress notes, the contents of documentation were incomplete or nonspecific with wound care being described as 'following the wound care pathway'. Some documentation included dressing choices and different products used, but failed to mention the wound healing process, wound bed status or signs of infections. This is
Table 4. Clinical characteristics of wounds $(n=60)$

\begin{tabular}{|c|c|c|}
\hline Wound category & Number & Percentage \\
\hline \multicolumn{3}{|l|}{ Surgical specialty } \\
\hline Orthopedic & 25 & 41.7 \\
\hline Gastrointestinal & 2 & 3.3 \\
\hline Ear, nose and throat & 4 & 6.7 \\
\hline Plastic & 18 & 30.0 \\
\hline Urology & 3 & 5.0 \\
\hline Vascular & 6 & 10.0 \\
\hline Neurosurgery & 2 & 3.3 \\
\hline Total & 60 & $100 \%$ \\
\hline \multicolumn{3}{|l|}{ Wound location } \\
\hline Head and face & 8 & 13.3 \\
\hline Abdomen & 8 & 13.3 \\
\hline Arms and hands & 2 & 3.3 \\
\hline Hip & 13 & 21.7 \\
\hline Knee, legs and toes & 26 & 43.3 \\
\hline Back and spinal & 3 & 5.0 \\
\hline Total & 60 & $99.9 \%$ \\
\hline
\end{tabular}

somewhat concerning given that signs of wound infection, such as pain or tenderness, redness, swelling, wound incision and healing status are important indicators for diagnosing SSI. ${ }^{20}$ It appears that in this acute hospital, documentation in progress notes lacks specificity and standardisation in terms of what information is important to note in medical records.

Documentation is an important communication strategy for all health professionals to record and keep track of the wound's healing progress. We found that wound assessment charts were inconsistently used with only one-quarter of observations documented on charts and less than half of the items on the wound chart completed. Our findings are similar to previous studies where incomplete or omitted documentation has also been described. For example, in 2014, a chart audit was conducted on post-surgery wound assessment and management practices across one health-care services district in Queensland, Australia. ${ }^{37}$ It found that only about $40 \%$ of wound assessments were fully recorded. ${ }^{37}$ According to Wong, ${ }^{38}$ deficiencies exist in content of documentation, inadequate detail of patient care and inexplicit descriptions of nursing care have been observed. It is not clear what impacts documentation practice, although nursing research has put emphasis on clinical documentation to promote safe, effective and person-centered care. ${ }^{39}$

Conceivably, good documentation should improve multidisciplinary team communication and provide a legal, comprehensive, chronological record of the 


\section{practice}

Table 5. Frequencies of observed wound care behaviours as listed on the audit tool

\begin{tabular}{|c|c|c|c|c|c|c|c|c|c|c|c|}
\hline $\begin{array}{l}\text { Criterion } \\
\text { number }\end{array}$ & Items & Yes & $\%$ & No & $\%$ & $\begin{array}{l}\text { Criterion } \\
\text { number }\end{array}$ & Items & Yes & $\%$ & No & $\%$ \\
\hline 1 & $\begin{array}{l}\text { Dressing management: Use an } \\
\text { aseptic non-touch technique } \\
\text { for change or } \\
\text { remove dressings }\end{array}$ & & & & & 4.1 & $\begin{array}{l}\text { Did not use topical } \\
\text { antimicrobial agents on } \\
\text { surgery wounds healing by } \\
\text { primary intension }\end{array}$ & 17 & 28.3 & 43 & 71.7 \\
\hline 1.1 * & $\begin{array}{l}\text { Leave dressing intact for at } \\
\text { least } 48 \text { hours post procedure }\end{array}$ & 3 & 5.0 & 10 & 16.7 & 5 & $\begin{array}{l}\text { Wound assessment method: } \\
\text { the nurse checks the wound }\end{array}$ & & & & \\
\hline \multirow[t]{2}{*}{1.2} & \multirow[t]{2}{*}{$\begin{array}{l}\text { Handwashing before dressing } \\
\text { change, using soap and water, } \\
\text { or alcohol gel }\end{array}$} & \multirow[t]{2}{*}{57} & \multirow[t]{2}{*}{95.0} & \multirow[t]{2}{*}{3} & \multirow[t]{2}{*}{5.0} & & swelling, and fever) & & & & \\
\hline & & & & & & 5.1 & Direct observation & 60 & 100 & 0 & 0 \\
\hline $1.3^{*}$ & $\begin{array}{l}\text { Remove old dressing } \\
\text { with gloved hands }\end{array}$ & 56 & 93.3 & 3 & 5.0 & 5.2 & Tools used-specify in & 0 & 0 & 60 & 100 \\
\hline \multirow{2}{*}{$1.31 *$} & \multirow{2}{*}{$\begin{array}{l}\text { Wash hands after removing } \\
\text { old dressing }\end{array}$} & \multirow{2}{*}{56} & \multirow{2}{*}{93.3} & \multirow{2}{*}{3} & \multirow{2}{*}{5.0} & \multirow{3}{*}{6} & expranation comum & & & & \\
\hline & & & & & & & \multirow{2}{*}{$\begin{array}{l}\text { Documentation of wound care } \\
\text { process: where is } \\
\text { it documented? }\end{array}$} & & & & \\
\hline 1.32 * & $\begin{array}{l}\text { Change gloves after removed } \\
\text { old dressing }\end{array}$ & 54 & 90.0 & 4 & 6.7 & & & & & & \\
\hline 1.6 & Aseptic fields & 51 & 85.0 & 9 & 15.0 & 6.1 & In progress notes & 44 & 73.3 & 16 & 26.7 \\
\hline \multirow[t]{3}{*}{1.7} & \multirow{3}{*}{$\begin{array}{l}\text { Environmental control: } \\
\text { no other avoidable infection } \\
\text { risks factors (such as } \\
\text { bed-making, patients using } \\
\text { commodes, or urinal bottles } \\
\text { with urine in them) }\end{array}$} & \multirow[t]{3}{*}{60} & \multirow[t]{3}{*}{100} & \multirow[t]{3}{*}{0} & \multirow[t]{3}{*}{0} & 6.2 & On wound assessment chart & 15 & 25.0 & 45 & 75.0 \\
\hline & & & & & & 6.3 & $\begin{array}{l}\text { Neither on wound chart nor in } \\
\text { progress notes }\end{array}$ & 15 & 25.0 & 0 & 0 \\
\hline & & & & & & 6.4 & $\begin{array}{l}\text { Both on wound charts and in } \\
\text { progress notes }\end{array}$ & 14 & 23.3 & 0 & 0 \\
\hline \multirow[t]{3}{*}{1.8 * } & \multirow{3}{*}{$\begin{array}{l}\text { Wear other protective } \\
\text { equipment if contamination is } \\
\text { expected: including } \\
\text { eye protection }\end{array}$} & \multirow[t]{3}{*}{28} & 46.7 & 10 & 16.7 & 6.5 & Other tools & 0 & 0 & 60 & 100 \\
\hline & & & & & & 7 & Documentation contents & & & & \\
\hline & & & & & & 7.1 & Type of wound & 5 & 8.3 & 55 & 91.7 \\
\hline 1.9 & $\begin{array}{l}\text { Hand washing after dressing } \\
\text { change using soap and water, }\end{array}$ & 49 & 81.7 & 11 & 18.3 & 7.2 & Duration of wound & 0 & 0 & 60 & 100 \\
\hline & or alcohol gel & & & & & 7.3 & Location of wound & 27 & 45.0 & 33 & 55.5 \\
\hline 2 & Cleansing solution & & & & & 7.4 & Dimension of wound & 4 & 6.7 & 56 & 93.3 \\
\hline 2.1 * & Use sterile saline for wound & 8 & 13.3 & 2 & 3.3 & & (length $\mathrm{x}$ width $\mathrm{x}$ depth) & & & & \\
\hline & $\begin{array}{l}\text { cleansing from post-op } \\
\text { to } 48 \text { hours after surgery if } \\
\text { dressing needs to be changed }\end{array}$ & & & & & 7.5 & $\begin{array}{l}\text { Clinical characteristics of } \\
\text { wound bed (red, pink, yellow, } \\
\text { black, undermined) }\end{array}$ & 16 & 26.7 & 44 & 73.3 \\
\hline $2.2^{*}$ & $\begin{array}{l}\text { Use tap water for wound } \\
\text { cleansing after } 48 \text { hours, and if } \\
\text { the wound has separated or } \\
\text { has been surgically opened to }\end{array}$ & 0 & 0 & 52 & 86.7 & 7.6 & $\begin{array}{l}\text { Wound edge appearance } \\
\text { (callus and scale, maceration, } \\
\text { erythema, edema) }\end{array}$ & 1 & 1.7 & 59 & 98.3 \\
\hline & drain pus & & & & & 7.61 & Periwound appearance & 11 & 18.3 & 49 & 81.7 \\
\hline 3 & Patient education & & & & & 7.62 & Exudate type and colour & 16 & 26.7 & 44 & 73.3 \\
\hline 3.1 * & $\begin{array}{l}\text { Advise patients that they may } \\
\text { shower safely } 48 \text { hours } \\
\text { after surgery }\end{array}$ & 0 & 0 & 47 & 78.3 & $7.7^{*}$ & $\begin{array}{l}\text { Infection: signs and symptoms } \\
\text { of infection documented }\end{array}$ & 3 & 5.0 & 10 & 16.7 \\
\hline & & & & & & 7.8 & Wound pain & 0 & 0 & 60 & 100 \\
\hline $3.2^{*}$ & $\begin{array}{l}\text { Educate patient on how to } \\
\text { care for wound after discharge }\end{array}$ & 18 & 30.0 & 37 & 61.7 & 7.9 * & Presence of foreign bodies & 0 & 0 & 0 & 0 \\
\hline & and ioliow-up wound care & & & & & 7.10 & Prior wound treatments and & 0 & 0 & 60 & 100 \\
\hline 4 & Topical antimicrobial agents & & & & & & their therapeutic outcome & & & & \\
\hline
\end{tabular}


surgical wounds' healing progress, management and prevention plan. ${ }^{19}$ AWMA $^{19}$ standards advocate the importance of wound documentation as it is part of the legal record that includes the patients' medical history, diagnostic examinations, wound assessment, wound management strategies and outcomes. Documentation can provide information to facilitate effective SSI surveillance and enable early identification of complications, leading to reduced incidence of SSI and morbidity/mortality rates among surgical patients. ${ }^{3}$

Documentation of wounds in our study could have been further limited by the retrospective nature of documentation practice, which often occurred several hours after assessment. This delayed reporting relied on memory when documenting important wound characteristics. While the importance of documentation has been highlighted by clinical guidelines, we have been unable to locate guidelines which specify optimal timing of documentation following wound assessment. As incomplete or delayed reporting can lead to inaccurate wound assessment result, delayed treatment for SSI which will ultimately impact on quality care delivery and may lead to adverse patients' outcomes. Gillespie et al. ${ }^{37}$ suggested that it is important to contemporaneously document wound assessment as close as practicable to the time when the wound care episode occurred to avoid relying on memory and improve accuracy of documentation.

In the facility where this study was conducted, important aspects of wound healing and specific contents of the wound assessment were missing on wound charts, specifically wound pain, wound edge or signs of infections. It is suggested that a comprehensive wound care pathway should contain accurate assessment, documentation, intervention procedures and the anticipated wound healing outcomes. ${ }^{40}$

It is possible that using additional data techniques such as the 'Think Aloud' method, together with retrospective probing, may have allowed us to understand in more detail nurses' underlying decision processes as they managed surgical wounds. ${ }^{41}$ Think Aloud is a technique used to gather data, to allow participants verbalize thoughts as they are performing certain tasks. ${ }^{42}$ This method can be used to include both concurrent and retrospective data collection. ${ }^{42}$ In 2015 , Gillespie et al. conducted a qualitative study with the aim of exploring health professionals' wound management decision-making process. ${ }^{43}$ Findings from that study suggested that the use of intuitive practicebased knowledge, patients' needs, costs, others' expertise and established practices were driving forces when developing treatment plans. ${ }^{43}$

Many factors may impact the assessment and documentation of surgical wounds in our study. Apart from nurses being busy in morning shifts when the bulk of wound care occurred, the time taken to perform wound care could be a contributing factor. Our study observed 'clean' surgical wounds healing by primary intention, for most 'clean' wound dressings observed,
Table 6. Frequencies of clean gloves and sterile gloves usage

\begin{tabular}{|c|c|c|c|c|c|}
\hline $\begin{array}{l}\text { Criterion } \\
\text { number }\end{array}$ & Items & Yes & $\%$ & No & $\%$ \\
\hline 1 & Indications for gloves usage & & & & \\
\hline 1.1 & $\begin{array}{l}\text { Clean gloves in non-touch } \\
\text { technique is indicated (gloved } \\
\text { hand does not touch wound, and/ } \\
\text { or dressing) }\end{array}$ & 42 & 70.0 & 18 & 30.0 \\
\hline 1.2 & $\begin{array}{l}\text { Sterile gloves touching the wound } \\
\text { and/or dressing is indicated (if } \\
\text { gloved hand touching the wound } \\
\text { and/or dressing is unavoidable) }\end{array}$ & 18 & 30.0 & 42 & 70.0 \\
\hline 2 & Observed gloves usage & & & & \\
\hline 2.1 & $\begin{array}{l}\text { Used clean gloves correctly } \\
\text { in non-touch technique }\end{array}$ & $26 / 42$ & 61.9 & $16 / 42$ & 38.1 \\
\hline 2.2 & $\begin{array}{l}\text { Used sterile gloves correctly } \\
\text { when indicated }\end{array}$ & $14 / 18$ & 77.8 & $4 / 18$ & 22.2 \\
\hline 2.3 & $\begin{array}{l}\text { Clean gloves were indicated but } \\
\text { sterile gloves were used }\end{array}$ & 8 & & & \\
\hline 2.4 & $\begin{array}{l}\text { Sterile gloves were indicated but } \\
\text { clean gloves were used }\end{array}$ & 3 & & & \\
\hline
\end{tabular}

wound care generally took about 10-15 minutes from the time nurses entered the room to task completion. It is possible that insufficient time was allocated to thorough wound assessment which is necessary to detect early warning signs of SSI. It is presumed that may also be that simple surgical wounds are considered straight forward and consequently are not afforded the same level of assessment and documentation as complex wounds. Emphasising the importance of comprehensive and complete assessment and documentation is essential to promote SSI prevention.

\section{Strengths and limitations}

Our results indicate several areas for improvement which require further exploration using qualitative methods; however, we acknowledge some limitations. The issues surrounding assessment and documentation of surgical wound care may, to some extent, be contextual-that is, hospital-specific. The use of a convenience sample, drawn from a single hospital limits the extent to which these results may be generalised to other contexts, such as community care settings and multicentre care facilities. The data in our study is limited in that we collected data through direct observation and from completed wound assessment charts (which were completed only about a quarter of the time).

Additionally, the sample may be diluted due to multiple surgical procedures. While it was not our intention to assess group differences, tests of significance were not possible due to small sample sizes within each group. However, we included observation of acute wounds healing by primary intention with a variety of wound location and wound characters, 
providing valuable information for the management of different clean surgical wounds.

Although we collected data from only 60 participants, our results were consistent with previous research 25,26 indicating that surgical wound management practices do not reflect the current evidence based guidelines. Additionally, we did not purposely collect the information on time used on dressing change, the observer observed that the estimated time for each dressing change lasted between 10-15 minutes and we acknowledge it would be useful to know the proportion of time that nurses' spent on wound assessment/ observations in relation to wound care during and after the 48-hour period. Nevertheless, real-time observational study is consistent with our aims; we have identified possible deviations from recommended practice in this study.

Furthermore, during data collection the researcher refrained from asking the nurses questions to avoid interfering with or influencing decision making. The use of Think Aloud as an additional data collection strategy may have helped us to explore decision-making processes during wound assessment. Future research may include the use of Think Aloud methods to glean insights into clinical factors that drive nurses' decisions in wound care.

It is also possible that the observational nature of this study may have caused nurses to alter their wound care behaviors in some way. To mitigate this effect, the research observer carried out the observations in an unobtrusive manner and was positioned away from the nurses' work area during their wound management.

\section{Conclusion}

In conclusion, due to the arising number of surgeries being performed every year, increased burden to patients' and health-care system and associated mortality rate, SSI remains a challenge for postoperative care and wound management. Appropriate surgical wound management, including aseptic technique, patients' wound care education, accurate wound assessment and documentation, is important for surgical patients' safety. These practices facilitate wound healing, enable clinical communication, promote quality improvement, and provide evidence for legal cases.

Our results indicate that there is a need to further explore a number of practice areas that may meet future improvement. There is a need to improve surgical wound management practices, especially aseptic technique, patient education on wound care, wound assessment and documentation practices. In this study, contemporaneous surgical wound management practices do not appear to be meeting the recommended standards in daily practice.

\section{Relevance to clinical practice}

SSI is preventable. ${ }^{18}$ Our results have identified important areas where practice change is needed to prevent HAIs, specifically SSI. Appropriate surgical wound care can reduce the incidence of SSIs. ${ }^{19}, 23$ Surgical wound care has a positive impact on reduced morbidity, mortality and hospital costs. Our study has identified an area of clinical practice that is not well described in the literature ${ }^{27}$ and the results highlight the importance of developing and implementing strategies to enable nurses to incorporate evidencebased wound care guidelines into clinical practice. Further research is needed to identify specific barriers and enablers to guideline adherence. Factors associated with nurses' wound care decision-making requires further exploration and would enhance understanding of this practice area. Jwc

\section{Acknowledgements}

Our study team gratefully acknowledges the financial support of the Centre for Research Excellence in Nursing (NCREN) of National Health and Medical Research Council (NHMRC) of Australia.

\section{References}

1 European Centre for Disease Prevention and Control. Surveillance of surgical site infections in Europe 2010-2011. 2013. http://tinyurl.com/zaqzzzr (accessed 13 December 2016). 2 Centers for Disease Control and Prevention. Data from the National Hospital Discharge Survey. 2010. http://tinyurl.com/gvnql3f

(accessed 13 December 2016) 3 Astagneau, P., L'Hériteau, F., Daniel, F., et al. Reducing surgical site infection incidence through a network: results from the French ISO-RAISIN surveillance system. J Hosp Infect 2009; 72: 2, 127-134. 4 National Collaborating Centre for Women's and Children's Health. Surgical Site Infection: Prevention and Treatment of Surgical Site Infection (Full version of Clinical Guideline 74, commissioned by the National Institute for Health and Care Excellence). RCOG

Press. 2008; 4-28.

5 Anderson, D.J., Podgorny, K.,

Berríos-Torres, S.I., et al.

Strategies to prevent surgical site infections in acute care hospitals: 2014 update. Infect Control Hosp Epidemiol 2014; 35: 6, 605-627. 6 Horan, T.C., Gaynes, R.P., Martone, W.J. et al. CDC definitions of nosocomial surgical site infections, 1992: a modification of CDC definitions of surgical wound infections. Infect Control Hosp Epidemiol 1992; 13: 10, 606-608.

7 Magill, S.S., Hellinger, W.,

Cohen, J. et al. Prevalence of

healthcare-associated infections in acute care hospitals in

Jacksonville, Florida. Infect Control Hosp Epidemiol 2012; 33: 3, 283-291.

8 Allegranzi, B., Bagheri Nejad, S.,
Combescure, C. et al. Burden of endemic health-care-associated infection in developing countries: systematic review and metaanalysis. Lancet 2011; 377: 9761, 228-241.

9 World Health Organization. Health care-associated infections fact sheet. N.D. http://tinyurl.com/ d2qwn9m (accessed 13 December 2016).

10 Zhang, Y., Zhang, J., Wei, D. et al. Annual surveys for pointprevalence of

healthcare-associated infection in a tertiary hospital in Beijing, China, 2012-2014. BMC Infect Dis 2016; 16: 161

11 Shepard, J., Ward, W.,

Milstone, A. et al. Financial impact of surgical site infections on hospitals: The hospital management perspective. JAMA

Surgery. 2013; 148: 10, 907-914.
12 de Lissovoy, G., Fraeman, K., Hutchins, V. et al. Surgical site infection: incidence and impact on hospital utilization and treatment costs. Am J Infect Control 2009; 37: 5, 387-397.

13 Anderson, D.J., Pyatt, D.G., Weber, D.J. et al. Statewide costs of health care-associated infections: estimates for acute care hospitals in North Carolina. Am J Infect Control 2013; 41: 9, 764-768.

14 Zimlichman, E., Henderson, D. Tamir, O. et al. Health careassociated infections: a meta-analysis of costs and financial impact on the US health care system. JAMA Internal Med 2013; 173: 22, 2039-2046. 15 Jenks, P.J., Laurent, M. McQuarry, S., Watkins, R. Clinical and economic burden of surgical site infection (SSI) and predicted 
financial consequences of elimination of SSI from an English hospital. J Hosp Infect 86: 1 24-33.

16 Lamarsalle, L., Hunt, B., Schauf, M. et al. Evaluating the clinical and economic burden of healthcare-associated infections during hospitalization for surgery in France. Epidemiol Infect 2013; 141: 12, 2473-2482. 17 Tanner, J., Davey, S., Padley, W., Brown, B. Patients' experiences of surgical site infection. Journal of Infection Prevention. 2012; 13: 5, 164-168. 18 Umscheid, C.A., Mitchell, M.D. Doshi, J.A. et al. Estimating the proportion of healthcareassociated infections that are reasonably preventable and the related mortality and costs. Infect Control Hosp Epidemiol 2011; 32: 2, 101-114.

19 Australian Wound Management Association. Standards for Wound Management. 2010. http://tinyurl. com/zdjy37a (accessed January 2017).

20 Mangram, A.J., Horan, T.C., Pearson, M.L. et al. Hospital Infection Control Practices Advisory Committee. Guideline for prevention of surgical site infection. Infect Control Hosp Epidemiol 1999; 20: 4, 250-278. 21 Rowley, S., Clare, S.

Macqueen, S., Molyneux, R. ANTT v2: An updated practice framework for aseptic technique. Br J Nurs 2010: 19: 5 Supp, S5-S11.
22 Gillespie, B.M., Fenwick, C. Comparison of the two leading approaches to attending wound care dressings. Wound Practice and Research 2009; 17: 2, 84-89. 23 National Health and Medical Research Council (NHMRC). Australian Guidelines for the Prevention and Control of Infection in Healthcare. Commonwealth of Australia; 2010. http://tinyurl.com/ gq5kc2s (accessed 3 January 2017).

24 Marshall, A.P., West, S.H., Aitken, L.M. Preferred information sources for clinical decision making: critical care nurses' perceptions of information accessibility and usefulness. Worldviews Evid Based Nurs 2011; 8: 4, 224-235.

25 Meeks, D.W., Lally, K.P., Carrick, M.M. et al. Compliance with guidelines to prevent surgical site infections: As simple as 1-2-3? Am J Surg 2011; 201: 1, 76-83. 26 Awad, S.S. Adherence to surgical care improvement project measures and post-operative surgical site infections. Surg Infect (Larchmt) 2012; 13: 4, 234-237. 27 Ding, S., Lin, F., Gillespie, B.M. Surgical wound assessment and documentation of nurses: an integrative review. J Wound Care 2016; 25: 5, 232-240.

28 Leon, A.C., Davies, L.L. Kraemer, H.C. The role and interpretation of pilot studies in clinical research. J Psychiatr Res 2011; 45: 5, 626-629.

29 Lancaster, G.A. Pilot and feasibility studies come of age! Pilot and Feasibility Studies. 2015; 1: 1, 1-4.

30 Hertzog, M.A. Considerations in determining sample size for pilot studies. Res Nurs Health 2008; 31 : 2, 180-191

31 Polit-O'Hara, D., Beck, C.T. Nursing research: generating and assessing evidence for nursing practice.(2nd edn) Wolters Kluwer/ Lippincott Williams \& Wilkins, 2012.

32 WHO. Guidelines on Hand Hygiene in Health Care: First Global Patient Safety Challenge Clean Care is Safer Care. N.D. http://tinyurl.com/hboudmz (accessed 3 January 2017)

33 Swenne, C., Alexandrén, K. Surgical team members' compliance with and knowledge of basic hand hygiene guidelines and intraoperative hygiene. Journal of Infection Prevention. 2012; 13: 4 114-119.

34 Loveday, H.P., Wilson, J.A. Pratt, R.J. et al. epic3: national evidence-based guidelines for preventing healthcare-associated infections in NHS hospitals in England. J Hosp Infect 2014; 86 Suppl 1: S1-S70.

35 Skoufalos, A Clarke, J.L. Napp, M. et al. Improving Awareness of Best Practices to Reduce Surgical Site Infection: A Multistakeholder Approach. Am Med Qual 2012; 27: 4, 297-304. 36 Hari, M., Rosenzweig, M.

Incidence of preventable postoperative readmissions following

pancreaticoduodenectomy: mplications for patient education. Oncol Nurs Forum 2012; 39: 4 408-412.

37 Gillespie, B.M., Chaboyer, W. Kang ,E. et al. Postsurgery wound assessment and management practices: a chart audit. J Clin Nurs 2014; 23: 21-22, 3250-3261. 38 Wong, F.W. Chart audit: strategies to improve quality of nursing documentation. J Nurses Staff Dev 2009; 25: 2, E1-E6. 39 Kent, P., Morrow, K. Better documentation improves patient care. Nurs Stand 2014; 29: 14 44-51.

40 Hess, C.T. Assessment + documentation = outcomes. Adv Skin Wound Care 2010; 23: 1, 48. 41 Aitken, L.M., Marshall, A,

Elliott, R., McKinley, S.

Comparison of 'think aloud' and observation as data collection methods in the study of decision making regarding sedation in intensive care patients. Int J Nurs Stud 2011; 48: 3, 318-325.

42 Ericsson, K.A., Simon, H.A. How to Study thinking in everyday life: contrasting think-aloud protocols with descriptions and explanations of thinking. Mind, Culture, and Activity 1998; 5: 3, 178-186.

43 Gillespie, B.M., Chaboyer, W, St John, W. et al. Health professionals' decision-making in wound management: a grounded theory. J Adv Nurs 2015; 71: 6 , 1238-1248.

\section{Wound Care Handbook}

The essential guide to product selection

- Need to know what new products are available at your fingertips?

- Ever wonder which product is the best for your patient? 